\title{
Research on the allelopathic potential of wheat
}

\author{
Yau Lam ${ }^{1}$, Cho Wing Sze ${ }^{1}$, Yao Tong ${ }^{1}$, Tzi Bun $\mathrm{Ng}^{2}$, Sydney Chi Wai Tang ${ }^{3}$, James Chung Man \\ $\mathrm{Ho}^{3}$, Qiaoqing Xiang ${ }^{4}$, Xiao Lin ${ }^{5}$, Yanbo Zhang ${ }^{1^{*}}$ \\ ${ }^{1}$ School of Chinese Medicine, The University of Hong Kong, Hong Kong, China; \\ *Corresponding Author: ybzhang@hkucc.hku.hk \\ ${ }^{2}$ The School of Biomedical Sciences, The Chinese University of Hong Kong, Hong Kong, China \\ ${ }^{3}$ Department of Medicine, The University of Hong Kong, Hong Kong, China \\ ${ }^{4}$ Department of Pulmonary Respiration, The Fuling Centre Hospital, Chongqing, China \\ ${ }^{5}$ The Fuling Centre Hospital, Chongqing, China
}

Received 2 August 2012; revised 16 September 2012; accepted 27 October 2012

\begin{abstract}
Objective: This paper mainly discusses the Allelopathic potential of wheat. Methods: This paper is prepared by reviewing the latest academic literatures. Result: The green revolution in the 1960s caused an increase in the demand for food. The agricultural sector and farmers tended to spend more time on the agricultural work but the crop yield was suppressed by the weeds. Hence, the usage of herbicide insecticides, fungicides and others chemicals had been increased. Although herbicides are efficient for weed controls, the continuous uses had gradually stimulated the weeds developing an effecttive resistance to the chemicals. Wheat (Triticum aestivum L.) is known as allelopathic against crops and weeds. Allelopathy of wheat (Triticum aestivum $L$.) has been extensively examined for its potentials in weeds management. The al- lelopathic activity of wheat has been attributed to hydroxamic acids, the related compounds and phenolic acids. Therefore, it could effectively reduce herbicide uses in order to maintain an eco-friendly environment and a cost-effective weed control.
\end{abstract}

Keywords: Wheat; Allelopathic Effect; Allelopathic Crop; Straw; Stubble; Benzoxazinones; Phenolics

\section{INTRODUCTION}

The green revolution in the 1960s and increased demand for food. The agricultural sector and farmers also tend to spend more time outside agricultural work. But the weeds are a major constraint limiting crop yield in agricultural systems and in organic systems in particular [1]. Weeds reduce crop yield by $5 \%$ in the most highly developed countries, $10 \%$ in the less developed countries and $25 \%$ in the least developed countries. Hence, herbicide insecticides, fungicides and others use has been increased in the last few decades. A herbicide use has been increased many fold. According to the statistics of the total pesticides used worldwide, herbicides accounts for $37 \%$, while $24 \%$, $9 \%$ and $29 \%$ are insecticides, fungicides and others. In which 332 herbicide resistant biotypes including 189 species (113 broad-leaved and 76 grasses) have been reported in more than 0.30 million fields worldwide. Although herbicides are efficient for weed control, continuous use has caused the development of resistance in weeds against several herbicides [2]. Furthermore, herbicides also pollute the soil, water and aerial environments and herbicide residues in food have deteriorated food quality and enhanced the risk of disease [3]. Therefore, there is growing public as well as scientific concern about the use of herbicides.

\section{ALLELOPATHIC EFFECT OF WHEAT}

Allelopathy is a phenomenon in which one plant inhibits growth of other plants through release of al- lelochemicals. It is a phenomenon in which the second- dary metabolites, produced by plants, microorganisms, viruses, and fungi stimulate or suppress the growth and development of agricultural and biological systems (ex- cluding animals). The crops inhibit weeds-A very pro- mising, it has emerged as an alternative to synthetic her- bicides for weed management in field crops [4,5]. It can reduce herbicide use to obtain eco-friendly and cost- effective weed control. Earlier, confirmed, a large num- ber of crops and trees has been found to possess allelo- pathic potential [6]. International research on the allelo- pathy of wheat is active [7]. Research on wheat allelopa- thy has progressed rapidly from the initial phase of eva- luation of wheat allelopathy to the identification of wheat allelochemicals, the degradation of these compounds and, 
further, to the identification of genetic markers associated with wheat allelopathy $[8,9]$.

\subsection{Straw of Wheat}

Wheat (Triticum aestivum L.) is known to be allelopathic against crops and weeds. Wheat straw reduced weed densities and biomass by an average of $90 \%$ compared with those plots without residues. Also, reported that wheat straw caused $16.8 \%$ reduction of broad-leaved weeds [10]. But aqueous leachate of wheat straw and the extract of decomposed wheat straw inhibit the growth of wheat. Display the aqueous extracts of wheat residues at 2 and $4 \%$ concentration significantly inhibited germination and growth. Wheat straw was decomposed under laboratory conditions at $\mathrm{pH}=5,7$ and 8 [11]. Study display that, $\mathrm{pH}=7$ showed very strong inhibition of wheat seed germination. Also, all acidic extracts can inhibit the growth of some plant growthand inhibited the germination and root growth of test species [12]. Chemical analysis indicated that syringoylglycerol 9-O-b-D-glucopyranoside inhibited the roots growth of lettuce and cress at concentrations greater than 0.1 and $10.0 \mathrm{lM}$, respectively. On the other hand, L-tryptophan inhibited the roots growth of lettuce and cress at concentrations greater than 0.1 and $1.0 \mathrm{lM}$, respectively. The content of syringoylglycerol 9-O-b-D-glucopyranoside and L-try-ptophan in the leachate of wheat straw (100 g eq./L) was $18.4 \pm 0.7$ and 6.2 $\pm 0.6 \mathrm{lM}$, respectively. Syringoylglycerol 9-O-b-D-glucopyranoside (18.4 lM) showed 21.5 and 13.5\% inhibition in the lettuce and cress roots assay, respectively. On the other hand, 6.2 lM of L-tryptophan showed 47.5 and $35.0 \%$ inhibition in the lettuce and cress roots assay, respectively [13]. In which, phenolic acids and organic acids have a strong inhibition effect. Nitrogen (N)-containing chemicals had a weaker inhibition effect and, in some cases, a stimulation effect [14].

\subsection{Stubble of Wheat}

Retention of crop stubbles is a key component of conservation farming systems, which are promoted worldwide [15]. Stubble mulching changes the conditions at the air and soil interface and influences the physical, chemical, and biological properties of the soil. Retained crop stubbles reduce soil evaporation, erosion and degradation, increase water availability to crops and maintain soil organic matter. In addition, stubble mulching efficiently controls weed propagation and enhances the capacity of crops to compete with weeds for growth resources. These changes have a large effect on the growth and development of crops. Thus, stubble mulching has ecological, social, and economic benefits and is important for the sustainable development of agriculture [16, 17]. Despite these benefits to production and sustainabi- lity, adoption has been slow in many areas of the world [18]. In the United States and Australia and show that retained crop stubbles can reduce the yield of crops [19]. Experiments demonstrate that poor growth of canola through surface-retained wheat stubble is primarily related to the physical effects of the stubble rather than biochemical effects related to stubble phytotoxicity or $\mathrm{N}$ -Immobilisation. Wheat stubble on canola of development was delayed, LAI and RMR were reduced, hypocotyls were longer, and SRL was increased. Fifty-two days after sowing, surface-mulch reduced total plant biomass through a reduction in both the number of plants per unit area as well as a reduction in individual plant size. Subsequent growth and final seed yield was also reduced to the same extent (26\%) [20]. An accompanying paper focuses on more detailed investigations of the physical impacts of the stubble on canola growth, particularly the impact of reduced light penetration through stubble on growth of canola seedlings. This suggests that elongation of the hypocotyl in canola in response to reduced and/or altered quality and quantity of light during emergence and delayed development the growth reduction caused by the hypocotyls elongation in the $50 \mathrm{~mm}$ tubes was on average $57 \%$ [21].

\section{AIIELOPATHIC SUBSTANCE OF WHEAT}

Wheat (Triticum aestivum) has been extensively studied for its allelopathic potential. The common allelochemicals from crop plants are generally secondary metabolites. These include phenolics, terpenoids, alkaloids, coumarins, tannins, flavonoids, steroids and quinines. The allelopathic activity of wheat has been attributed to hydroxamic acids and related compounds and phenolic acids [22]. In general, the allelochemicals of plants to the environment is as follows: 1) exudation from roots, 2) leaching from plants by fog, mist and rain, 3) decomposition of residues [23]. In which, crop plant root exudation has been chemically investigated from as early as 1921 when Lyon and Wilson studied the liberation of organic substances through the roots of growing plants. Further suggest that organic substances can interfere with basic processes of receiver plants as photosynthesis, cell division, respiration and protein synthesis [24] and indirectly provoke other forms of stresses. Another important effect of these allelochemicals is the activation of cellular antioxidant system in response to uncontrolled production and accumulation of reactive oxygen species [25]. Rovira has written a review covering plant root exudation. Allelopathic secondary metabolites such as methoxyphenylacetic acid have been observed to move from one plant to another through their root systems and as one of the important world crops, the root exudates from 
wheat have become a focus of allelopathic study [26-29].

\subsection{Benzoxazinones}

Benzoxazinones present in exudates from Triticum aestivum pointed to the presence of such constituents as DIMBOA, 2,-dihydroxy-1,4 benzoxazin-3-one (DIBOA), 2-hydroxy-1,4-benzoxazin-3-one (HBOA), 2-hydroxy7-methoxy, 1, 4-benzoxazin-3-one (HMBOA), and 2,7dihydroxy-1,4-benzoxazin-3-one (DHBOA). Of these benzoxazinones, only DIBOA and DIMBOA are hydroxamic acids (hydroxyl group on the nitrogen atom at position 4) [31]. In which, wheat with high concentrations of tramine or hydroxamic acids are very useful for a rotation in an area with high aphid populations. This is very profitable for the development of natural herbicides and resistances varieties [32].

\subsection{Phenolics}

Phenolics are the most common water-soluble allelochemicals known to play a significant role in plantPlant interactions, including allelopathy [33,34]. Several studies indicate that phenolics, upon entering the soil, are sorbed, detoxified or transformed to simpler forms, phenolics may markedly suppress weed growth in field when they influence nutrient uptake and may even serve as a carbon source for microbes [35].

\section{GENETIC GENES}

Allelopathy in wheat is complex and determined by many known, partially known, and unknown factors. It has been described as a dark grey system (grey theory) [36]. Allelopathic potential in wheat and genetic, chemical and ecological factors and a synergistic relationship.

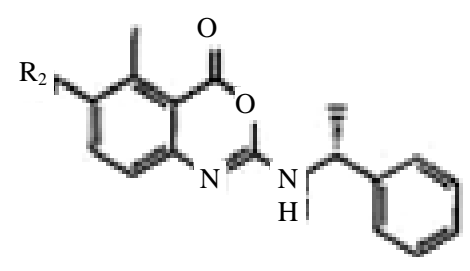

Figure 1. A series of 2-amino substituted benzoxazinones [30].

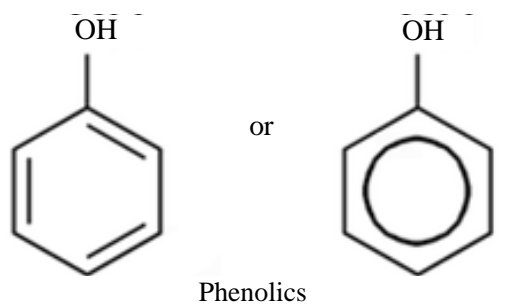

Figure 2. This picture come from Google: life.illinois.edu.
Heritability and its degree of influence on yield were more evident in the vegetative growth stage compared to the reproductive stage. Research indicated that allelopathic effects exhibited high heritability (55\% - 95\%) throughout the life cycle of wheat. In which, Heritability was highest in the tillering stage and weakest in the seed filling stage [37]. Allelopathic potential varied and was discontinuous throughout the wheat life cycle. Implying that multiple genes participated in the expression of allelopathy. In addition, that genotype $\cdot$ tillage interaction was reported in tests involving diverse genotypes. In a comparison of a conventional cultivar (Janz) and a novel experimental line (Vigor 18) bred for high leaf vigour, found that the latter grew best in unploughed soil. They suggested faster root growth, different exudates promoting more beneficial rhizosphere microflora, or modified shoot responses as possible mechanisms for the superior growth of Vigor 18. Hence, vigorous genotypes may present an opportunity for increased productivity under reduced tillage [38]. The genetic background for allelopathic potential in crops and the inner genetic mechanisms for allelopathic potential are gradually becoming known through the introduction of molecular biological techniques [39]. For example; Wheat-rye translocations involving $1 \mathrm{RS}$ are also widely used in wheat breeding programmes [40] and have been shown to improve root characteristics, it to be used in breeding programmes to improve weed suppression ability of wheat. The most triticale cultivars, weed biomass could be reduced by $18 \%$ - $28 \%$. If early vigour is also improved to the level of triticale, weed biomass could be reduced by $40 \%$ $60 \%$. In spring wheat, an improvement of PAAr by $20 \%$ resulted in an average reduction in weed biomass of four near isogenic breeding lines by $19 \%$ [41]. Some of the wheat-rye substitution lines showed a PAA value as high as $63 \%$. Further screening it may be possible to find lines with perhaps $70 \%$ root inhibition or more. PAA values of that magnitude in new wheat cultivars could provide a viable alternative to the use of herbicides or at least allow reduced use of herbicides [42].

\section{TOXICITY OF WHEAT ALLELOPATHY}

Autotoxicity is an intraspecific allelopathy occur when a plant species releases chemical substances that inhibit or delay germination and growth of the same plant species. Application of the concepts of allelopathy and autotoxicity in depicting the chemical interactions between varieties [43]. First appeared in an early report, who claimed that the roots of wheat, oats, and certain other crop plants exude chemicals inhibitory to their own seedlings. Since then, autotoxicity has been identified in many field crops, including alfalfa, rice, barley, wheat, asparagus and cucurbit crops $[44,45]$. Study display that, aqueous 
extract of wheat differed in varietal autotoxicity and varietal allelopathy, inhibiting wheat germination by $2 \%$ $21 \%$, radicle growth by $15 \%$ - 30\%, and coleoptile growth by $5 \%-20 \%$. These results suggest that careful selection of suitable wheat varieties is necessary in a continuous cropping system in order to minimize the negative impacts of varietal allelopathy and varietal autotoxicity [46]. Confirmation under controlled environments showed that wheat residue water extracts were autotoxic to the germination and seedling growth of wheat. In solution culture, Protic, et al., found that wheat seedling root volume, total root area and active root area were decreased with an increase in the quantity of the wheat residue amended into the nutrient solution $[47,48]$.

\section{ALLELOPATHIC CROP}

Wheat has caused allelopathic inhibition to the growth and yield of crops such as rice, barley, rye (Secale cereale L.), cotton (Gossypium hirsutum L. Merr) and soybean (Glycine max L. Merr). Wheat straw was also allelopathic to a number of forage crops including sorghum (Sorghum bicolor L. Moench), sunflower, pearl millet (Pennisetum glaucum L.), clusterbean (Cyamopsis tetragonoloba L.), cowpeas (Vigna unguiculata L. Walp.) and mulberry $[49,50]$.

\subsection{Sorghum and Sunflower (Example)}

Research indicates that, Sorghum and sunflower are well studied allelopathic crops [51,52]. Sorghum (Sorghum bicolor) is often chosen as a summer cover crop because of its rapid growth and ability to suppress weeds. Spring-planted sorghum residues provided up to $90 \%$ reductions in weed. Sorghum (Sorghum bicolor L.). It is the root hairs that are responsible for the exudation of the allelochemical. Contains gallic acid, protocateuic acid, syringic acid, vanillic acid, p-hydroxybenzoic acid, p-coumaric acid, benzoic acid, ferulic acid, m-coumaric acid, caffeic acids, p-hydroxybenzaldehyde and sorgoleone [53,54]. In which sorgoleone that the usefulness of early vigour and PAA to improve weed suppression is also dependent on the available genetic variation, heritability and whether the traits are correlated negatively or positively to yield. The usefulness of early vigour for breeding purposes is well documented, with high variation and heritability for 6this trait [55]. Other, sunflower (Helianthus annuus) shows strong weed suppression. Anaya reported that soil incorporation of sunflower residues markedly inhibited density of dicot weeds by $66 \%$ and controlled $85 \%$ of total weed growth. Sunflower possesses chlorogenic acid, isochlorogenic acid, $\alpha$-naphthol, scopolin and annuionones [56-59].

The sorghum and sunflower of many allelochemicals responsible for inhibitory action of these two crops have been identified. For example, mung bean (Vigna radiata), cotton (Gossypium hirsutum), wild oat and canary grass et al. In which, the sorghum (Sorghum bicolor L. Moench) and sunflower (Helianthus annuus L.) extracts for wild oat and canary grass management in wheat (Triticum aestivum). The sorghum + sunflower extracts combined of label rates of herbicides inhibited dry matter production of wild oat by up to $89 \%$ and canary grass by up to $92 \%$ [60-62]. Also, herbicide use can be reduced by up to $50 \%$. Further to explore the possibility of reducing herbicide use by $75 \%$ [63].

\subsection{Mulberry Allelopathy (Example)}

The allelopathic effects of mulberry on weeds and crops have been reported [64,65]. Can reduced the density and dry weight of weeds, In which included Bermudagrass. Bermudagrass has been classified as a noxious and common weed in the most cultivated areas of Africa, Australia, southern Europe, and Asia. It is considered to be one of the ten worst weeds in the world [66,67]. The mulberry (Morus alba) leaf water extracts on bermudagrass (Cynodon dactylon) and wheat (Triticum aestivum) were investigated. Four concentrations of extract (25\%, 50\%, $75 \%$, and $100 \%$ ) were compared with a control (distilled water).The results revealed that the pregermination application of $100 \%$ mulberry leaf water extract resulted in the complete inhibition of bermudagrass and wheat germination. However, postemergence, two foliar sprays suppressed only the growth of bermudagrass and promoted wheat growth. Further study display that the mulberry leaf water can decreased the germination of wheat when applied pre-emergence in the laboratory bioassay. However, the postemergence application significantly promoted wheat growth. The $100 \%$ mulberry leaf water extract had maximum activity on wheat. The selective action of the mulberry extract may be used as a foliar spray (early postemergence) at $12 \mathrm{~L}$ ha- 1 to increase the growth and yield of wheat [68].

\section{CONCLUSION}

Allelopathy has been a core theme of the agricultural research, it has been a complex and variable topic. The main reason for the variability of allelopathic crop materials involves effectiveness of cooperation and the antagonism mechanism. Modern agricultural research investigating it on the basis of genetic level mainly focusing on the relationship between each genetic factor which has achieved certain results, yet there still have been more potential problems to be further solved. Wheat is the stable food for the mankind, therefore, conducting more research on wheat allelopathy in regards to the effects to the yield and quality of crops is significant in order to contribute to the human life as a whole. 


\section{ACKNOWLEDGEMENTS}

This study was supported by Funding from Innovation and Technology Support Programme, the Government of the Hong Kong Special Administrative Region No. ITS/313/11 and Seed Funding Programme for Basic Research from The Hong Kong University No. 201111159043.

\section{REFERENCES}

[1] Lemerle, D., Verbeek, B. and Orchard, B. (2001) Ranking the ability of wheat varieties to compete with Lolium rigidum. Weed Research, 41, 197-209. doi:10.1046/j.1365-3180.2001.00232.x

[2] Fishel, F.M. (2007) Pesticide use trends in the US: Global comparison. Florida Cooperative Extension Service, Institute of Food and Agricultural Sciences, University of Florida, Gainesville.

[3] Ronal, D.E. (2000) Hand book of chemical risk assessment: Health hazards to humans, plants and animals, Vol. II. Lewis Publishers, Washington DC.

[4] Macias, F.A., Molinillo, J.M.G., Varela, R.M. and Galindo, J.C.G. (2007) Allelopathy-A natural alternative for weed control. Pest Management Science, 63, 327-348. doi:10.1002/ps.1342

[5] Jamil, M., Cheema, Z.A., Mushtaq, M.N., Farooq, M. and Cheema, M.A. (2009) Alternative control of wild oat and canary grass in wheat fields by allelopathic plant water extracts. Agronomy for Sustainable Development, 29, 475482. doi:10.1051/agro/2009007

[6] Zeng, R.S., Mallik, A.U. and Luo, S.M. (2008) Allelopathy in forested ecosystems. In: Zeng, R.S., Mallik, A.U. and Luo, S.M., Eds., Allelopathy in Sustainable Agriculture and Forestry, Springer, New York, 363-377.

[7] Yongqing, M.A. (2005) Allelopathic studies of common wheat (Triticum aestivum L.). Weed Biology and Management, 5, 93-104.

doi:10.1111/j.1445-6664.2005.00164.x

[8] Bertholdsson, N.O. (2005) Early vigour and allelopathy-Two useful traits for enhanced barley and wheat competitiveness with weeds. Weed Research, 45, 94-102. doi:10.1111/j.1365-3180.2004.00442.x

[9] Villagrasa, M., Guillamon, M., Labandeira, A., Taberner, A., Eljarrat, E. and Barcelo, D. (2006) Benzoxazinoid allelochemicals in wheat: Distribution among foliage, roots, and seeds. Journal of Agricultural and Food Chemistry, 54, 1009-1015. doi:10.1021/jf050898h

[10] Narwal, S.S.M.K., Sarmah, J.C. and Tamak (1998) Allelopathic strategies for wheat management in rice wheat rotation in northwestern India. In: Olofsdotter, M., Ed., Allelopathy in Rice. Proceedings of the Workshop on Allelopathy in Rice, 117-131.

[11] Ma, R.X., Liu, X.F., Yuan, G.L. and Sun, S.E. (1997) Study on the allelochemicals produced by bacteria and fungi in rhizosphere and their bioactivity. Acta Ecologica Sinica, 17, 449-452.

[12] Steinsiek, J.W., Oliver, L.R. and Collins, F.C. (1982) Allelopathic potential of wheat (Triticum aestivum) straw on selected weed species. Weed Science Society of America,
30, 495-497.

[13] Hiroshi N, Satoshi, M., Hideyuki, S. and Koji, H. (2006) Plant growth inhibitory compounds from aqueous leachate of wheat straw. Plant Growth Regulation, 48, 215-219.

[14] Ma, R.X., Liu, X.F., Yuan, G.L. and Sun, S.E. (1996) Study on allelochemicals in the process of decomposition of wheat straw by microorganisms and their bioactivity. Acta Ecologica Sinica, 16, 632-639.

[15] Chan, K.Y. and Pratley, J.E. (1998) Soil structural decline - Can the trend be reversed? In: Pratley, J.E. and Roberston, A., Eds., Agriculture and the Environmental Imperative, Commonwealth Scientific and Industrial Research Organisation (CSIRO), Melbourne, 129-163.

[16] Blum, U., King, L.D. and Brownie, C. (2002) Effects of wheat residues on dicotyledonous weed emergence in a simulated no-till system. Allelopathy Journal, 9, 159-176.

[17] Zuo, S.P., Ma, Y.Q. and Inanaga, S. (2008) Ecological adaptation of weed biodiversity to the allelopathic rank of the stubble of different wheat genotypes in a maize field. Weed Biology and Management, 8, 161-171. doi:10.1111/j.1445-6664.2008.00292.x

[18] Lyon, D., Bruce, S.E., Vyn, T. and Peterson, G. (2004) Global (USA \& Australian experiences) achievements and future challenges in conservation tillage. New Directions for a Diverse Planet: Proceedings of the 4th International Crop Science Congress, Brisbane, Australia.

[19] Bruce, S.E., Kirkegaard, J.A., Pratley, J. and Howe, G. (2005) Impacts of retained wheat stubble on canola in southern NSW. Australian Journal of Agricultural Research, 45, 1-12.

[20] Bruce, S.E., Kirkegaard, J.A., Pratley, J. and G, Howe. (2006) Growth suppression of canola through wheat stubble I. Separating physical and biochemical causes in the field. Plant and Soil, 281, 203-218. doi:10.1007/s11104-005-4251-7

[21] Bruce, S.E., Ryan, M.H., Hely, S., Kirkegaard, J.A. and Pratley, J.E. (2006) Causes of growth suppression of canola through wheat stubble II. Investigating impacts of hypocotyl elongation using simulated stubble. Plant and Soil, 281, 219-231. doi:10.1007/s11104-005-4643-8

[22] Wu, H., et al. (2001) Allelochemicals in wheat (Triticum aestivum L.): Variation of phenolic acids in shoot tissues. Journal of Chemical Ecology, 27, 125-135. doi:10.1023/A:1005676218582

[23] Rice, E.L. (1984) Allelopathy. 2nd Edition, Academic Press, London, 309-316.

[24] Duke, S.O. and Dyan, F.E. (2006) Mode of action of phytotoxins from plants. In: Reigosa, M.J., Pedrol, N. and Gonzalez, L., Eds., Allelopathy: A Physiological Process with Ecological Implications, Springer, Netherlands, 511536.

[25] Bogatwk, R. and Gniazdowska, A. (2007) ROS and phytohormones in plant-plant allelopathic interactions. Plant Signaling Behavior, 2, 317-318. doi:10.4161/psb.2.4.4116

[26] Lyon, T.L. and Wilson, J.K. (1921) Liberation of organic matter by roots of growing plants. New York State Agri- 
cultural Experiment Station-Cornell University, 40, 44 p.

[27] Rovira, A.D. (1969) Plant root exudates. Botanical Review, 35, 35-59. doi:10.1007/BF02859887

[28] Preston, W.H., Mitchell, J.W. and Reevf, W. (1954) Movement of alpha-methoxyphenylacetic acid from one plant to another through their root systems. Science, 119, 437-438. doi:10.1126/science.119.3092.437

[29] Khaliq, A., Matloob, A., Aslam, F. and BismllahI, K.M. (2011) Influence of wheat straw and rhizosphere on seed germination, early seeding growth and bio-chemical attributes of Trianthema portulacastrum. Planta Daninha, 29, 523-533. doi:10.1590/S0100-83582011000300006

[30] Norman, A., Abood, L.A.S., Daniel, L., Flynn, K.A. Houseman, A.J., Wittwer, Vickie, M., Dilworth, Paul, J., Hippenmeyer, Barry, C. and Holwerda. (1997) Inhibition of human cytomegalovirus protease by benzoxazinones and evidence of antiviral activity in cell culture. Bioorganic \& Medicinal Chemistry Letters, 7, 2105-2108. doi:10.1016/S0960-894X(97)00368-5

[31] Zhiqun, H., Terry, H., Hanwen, W.U., Min, A.N. and Jim, P. (2003) Correlation orrelation between phytotoxicity on annual ryegrass (Lolium rigidum) and production dynamics of allelochemicals within root exudates of an allelopathic wheat. Journal of Chemical Ecology, 29, 22632279.

[32] Rizvi, S.J.H. and Rizvi, V. (1992) Exploitation of allelochemicals in improving crop productivity. In: Rizvi, S.J.H. and Rizvi, V., Eds., Allelopthy: Basic and Applied Aspects, Chapman \& Hall, London, 443-472.

[33] Batish, D.R., Singh, J.K., Pandher, V., Arora and Kohli, R.K. (2002) Phytotoxic effect of parthenium residues on the growth of radish and chickpea and selected soil properties. Weed Biology and Management, 2, 73-78. doi:10.1046/j.1445-6664.2002.00050.x

[34] Batish, D.R., Tung, P., Singh, H.P. and Kohli, R.K. (2002) Phytotoxicity of sunflower residues against some summer season crops. Journal of Agronomy and Crop Science, 188, 19-24. doi:10.1046/j.1439-037x.2002.00526.x

[35] Liebl, R.A. and Worsham, A.D. (1983) Inhibition of pitted morning glory (Ipomoea lacunosa L.) and certain other weed species by phytotoxic compounds of wheat (Triticum aestivum L.) straw. Journal of Chemical Ecology, 9, 1027-1043. doi:10.1007/BF00982209

[36] Zhou, X.G., Zhang, Z.B. and Xu, P. (2005) Discussion of main breeding goals in wheat based on greysystems method (with English abstract in Chinese). System Sciences and Comprehensive Studies in Agriculture, 21, 81-84.

[37] Zuo, Y.Q. and Ma, S. (2007) Inanaga. Allelopathy variation in dryland winter wheat (Triticum aestivum L.) accessions grown on the Loess. Plateau of China for about fifty years. Genetic Resources and Crop Evolution, 54, 1381-1393. doi:10.1007/s10722-006-9123-3

[38] Watt, M., Kirkegaard, J.A. and Rebetzke, G.J. (2005) A wheat genotype developed for rapid leaf growth copes well with the physical and biological constraints of unplowed soil. Functional Plant Biology, 32, 695-706. doi:10.1071/FP05026

[39] Olofsdotter, M. (2001) Getting closer to breeding for competitive ability and the role of allelopathy-An example from rice (Oryza sativa). Weed Technology, 15, 798-806.

doi:10.1614/0890-037X(2001)015[0798:GCTBFC]2.0.C $\underline{0 ; 2}$

[40] Rabinovich, S.V. (1998) Importance of wheat-rye translocations for breeding modern cultivars of Triticum aestivum L. Euphytica, 100, 323-340. doi:10.1023/A:1018361819215

[41] Bertholdsson, N.O. (2010) Breeding spring wheat for improved allelopathic potential. Weed Research, 50, 4957. doi:10.1111/j.1365-3180.2009.00754.x

[42] Sharma, S., Bhat, P.R., Ehdaie, B., Close, T.J., Lukaszewski, A.J. and Waines, J.G. (2009) Integrated genetic map and genetic analysis of a region associated with root traits on the short arm of rye chromosome 1 in bread wheat. Theoretical and Applied Genetics, 119, 783-793. doi:10.1007/s00122-009-1088-0

[43] Putnam, A.R. (1985) Allelopathic research in agriculture: Past highlights and potential. In: Thompson, A.C. Ed., The Chemistry of Allelopathy: Biochemical Interactions among Plants, American Chemical Society, Washington, DC, 1-8. doi:10.1021/bk-1985-0268.ch001

[44] Ben, H.M., Ghorbal, M.H., Kremer, R.J. and Oueslati, O. (2002) Autotoxicity of barley. Journal of Plant Nutrition, 25, 1155-1161. doi:10.1081/PLN-120004379

[45] Yu, J.Q., Sen, S., Ya, Q., Zhu, Z. and Wen, H. (2000) Autotoxic potential of cucurbit crops. Plant and Soil, 223, 147-151. doi:10.1023/A:1004829512147

[46] Wu H.W., Jim, P., Deirdre, L. and De, L.L. (2007) Autotoxicity of wheat (Triticum aestivum L.) as determined by laboratory bioassays. Plant and Soil, 296, 85-93. doi:10.1007/s11104-007-9292-7

[47] Alam, S.M. (1990) Effect of wheat straw extract on the germination and seedling growth of wheat (cv. Pavon). Wheat Information Service, 71, 16-18.

[48] Protic, R., Andelic, M. and Vasiljevic, L. (1980) Anatomical structure and function of the root system of wheat as dependent on allelopathic effects. Savremena Poljoprivreda, 28, 243-256.

[49] Hicks, S.K., Wendt, C.W., Gannaway, J.R. and Baker, R.B. (1989) Allelopathic effects of wheat straw on cotton germination, emergence, and yield. Crop Science, 29, 1057-1061. doi:10.2135/cropsci1989.0011183X002900040048x

[50] Narwal, S.S., Sarmah, M.K. and Nandal, D.P. (1997) Allelopathic effects of wheat residues on growth and yield of fodder crops. Allelopathy, 4, 111-120.

[51] Khaliq, A., Aslam, Z. and Cheema, Z.A. (2002) Efficacy of different weed management strategies in mungbean (Vigna Radiata L.). International Journal of Agriculture and Biology, 4, 237-239.

[52] Iqbal, J., Cheema, Z.A. and Mushtaq, M.N. (2009) Allelopathic crop water extracts reduced the herbicide dose for weed control in cotton (Gossypium hirsutum L.). International Journal of Agriculture and Biology, 11, 360366.

[53] Netzly, D.H. and Butler, L.G. (1986) Roots of sorghum 
exude hydrophobic droplets containing biologically active components. Crop Science, 26, 775-780. doi:10.2135/cropsci1986.0011183X002600040031x

[54] Cheema, Z.A., Mushtaq, M.N., Farooq, M., Hussain, A. and Din, I.U. (2009) Purple nutsedge management with allelopathic sorghum. Allelopathy Journal, 23, 305-312.

[55] Wilson, R.E. and Rice, E.L. (1968) Allelopathy as expressed by Helianthus annuus and its roleinoldfield succession. Bulletin of the Torrey Botanical Club, 95, 432448. doi:10.2307/2483475

[56] Macias, F.A., Varela, R.M., Torres, A., Oliva, R.M. and Molinillo, J.M.G. (1998) Bioactive norsesquiterpenes from Helianthus annuus with potential allelopathic activity. Phytochemistry, 48, 631-636. doi:10.1016/S0031-9422(97)00995-3

[57] Macias, F.A., Torres, A., Galindo, J.L.G., Varela, R.M., Alvarez, J.A. and Molinillo, J.M.G. (2002) Bioactive terpenoids from sunflower leaves cv. Peredovick. Phytochemistry, 61, 687-692. doi:10.1016/S0031-9422(02)00370-9

[58] Anaya, A.L. (1999) Allelopathy as a tool in the management of biotic resources. Critical Reviews in Plant Sciences, 18, 697-739. doi:10.1080/07352689991309450

[59] Bell, A.R. and Nalewaja, J.D. (1968) Competition of wild oat in wheat and barley. Weed Science, 16, 505-508.

[60] Malik, R.K. and Singh, S. (1995) Little seed canarygrass (Phalarisminor) resistance to isoproturon in India. Weed Technology, 9, 419-425.
[61] Hobbs, P.R. and Sayre, K.D. (1998) Monasterio, jio. Increasing Wheat yields sustainably through agronomic means. NRG Paper, 98-101.

[62] Weston, L.A. and Duke, S.O. (2003) Weed and crop allelopathy. Critical Reviews in Plant Sciences, 22, 367-389. doi:10.1080/713610861

[63] Khanh, T.D., Chung, M.I., Xuan, T.D. and Tawata, S. (2005) The exploitation of crop allelopathy in sustainable agricultural production. Journal of Agronomy and Crop Science, 191, 172-184. doi:10.1111/j.1439-037X.2005.00172.x

[64] Mughal, A.H. (2000) Allelopathic effect of leaf extract of Morus alba $L$. on germination and seedling growth of some pulses. Range Management and Agroforestry, 21, 164-169.

[65] Hong, N.H., Xuan, T.D., Eiji, T. and Khanh, T.D. (2004) Paddy weed control by higher plants from Southeast Asia. Crop Protection Journal, 23, 255-261. doi:10.1016/j.cropro.2003.08.008

[66] Horowitz, M. (1996) Bermudagrass (Cynodon dactylon): A history of the weed and its control in Israel. Phytoparasitica, 24, 305-320. doi:10.1007/BF02981413

[67] Holm, L. (1969) Weed problems in developing countries. Weed Science, 17, 113-118.

[68] Razia, A.H., Mumtaz, H.Z. and Ata, C. (2010) Mulberry leaf water extract inhibits bermudagrass and promotes wheat growth. Weed Biology and Management, 10, 234240. doi:10.1111/j.1445-6664.2010.00389.x 